\section{GEOGRAPHY IN THE JUNIOR HIGH SCHOOL}

\author{
Report of the National Council Committee \\ on High School Geography
}

\section{The New Curriculum}

A $\mathrm{N}$ EXAMINATION of the literature, ever increasing in volume, on the curriculum reveals the fact that there is a new spirit at work in our schools, a spirit that is a response to the many problems growing out of our tremendous industrial development, the rapid growth of urban industrial centers, the increasing utilization and rapid depletion of many of our natural resources, out of the wonderful improvement in transportation and communication, the expansion of our overseas commerce, our increasing participation in international affairs, and the tremendous expansion of our mental horizon.

The schools must ever reflect the trend of the times, for how else can they perform the duties imposed upon them? Modern life is quite different from life in pioneer days when the child was from birth in direct contact with the environment from which he later must attempt to wrest a living and play his part as a citizen. The pioneer's world was a crude farming world, in which local economy prevailed. Economic, social, and political life was simple. School life did not need to imitate the everyday life of the world, for the child participated freely in his out-of-school activities in the affairs of his neighborhood. $\mathrm{He}$ attended threshings, barn raisings, logging "bees," town meetings, and even business meetings of the church fathers. He was in close touch with practically every phase of community life. The "three R's" then taught might suffice; but now we are living in a world of machines which multiplies man's power many fold. Production, transportation,

Reprinted from The Journal of Geography, Vol. XXVI, No. 6, September, 1927. communication are now almost entirely machine performed. The child of today even in the most favorable environment comes in contact with only such specialized forms of activity that a highly complex industrial civilization permits. A new type of education is therefore needed. It must be an education that will aid the developing child to understand and participate in the work of the everyday, pulsating world. It must do something more. It must, with specific knowledge-information, and sources of information-specific procedures, and successful practice in self-expression and self-sacrifice (the essentials of strength of character in a democracy) educate the child to feel the zest of search and responsibility for choice in the changing civilization. Both the cultural, or avocational, and utilitarian, or vocational aims must therefore be realized through the course of study.

No subject, unless it can in some measure supply worthwhile elements of the program sketched above, should hope to claim a place in the new curriculum.

\section{The "Claims" of Geography as a Junior High School Subject}

That geography as a socialized subject has had its values inexcusably ignored by most of our schools can scarcely be denied by any one who takes the trouble to analyze the facts. This mistake must not be perpetuated.-Davis in "Junior High School Education," p. 186.

The study of geography offers a larger and wider opportunity for a vital and comprehensive study of human life in its environmental relations than any school subject established or proposed. - Henry Suzzallo.

Within the last decade or two a new spirit has been at work in shaping the content of elementary and secondary school geography - a spirit of the practical. In all our better schools today the geography curriculum presents usable information that deals with the experiences of men and nations in their economic and political adjustments to their physical environments. Geography today is essentially an interpretative study of:

1. The great industries of continents and regions: agriculture, lumbering, fishing, mining, manufacturing; 
2. Of trade and transportation;

3 . Of the need and the methods of conservation of our natural resources: waterpower, minerals, forests, soil, and human life and property:

4. Of the ideals, aspirations, and problems of nations;

5. Of the geographic factors at the basis of the international problems of today;

6 . Of the political, economic and commercial ties that bind the nations into a world family;

7. And because it is geography-traditionally a study of the earth and man-it discusses each of these in their specific physiographic and climatic setting. It aims at the establishment of principles that underlie these economic and political activities of man and at the development of a geographic "spirit" that utilizes facts and principles in the solution of problems in the field of economic, political, and social geography. It takes first rank as a high school subject in teaching human adjustment to the present day social, economic, political, and international conditions, and in demonstrating the laws of geographic adaptation, $i . e_{\text {., }}$ the ultization of the resources of the earth.

Although geography has a place in the elementary school, its field is so large, its material so valuable and so closely linked with the present everyday changing world, it should have a prominent place in the high school. A. S. Goldsborough, late Executive Secretary of the Baltimore Association of Commerce, has well said:

The high school graduate cannot get along in the changing-ever changing-business world on the geographic facts learned when he was an elementary school pupil. Geography is a dynamic subject which loses vitality if not kept up to date.

Geography, because it presents interesting up-to-date practical information, offers opportunity for good straight thinking on problems of effective citizenry. Because it deals with natural resources and their conservation, because it reveals our potentialities as an agricultural nation, as a manu- facturing nation, and as a world power, and because it interprets the economic activities and opportunities of the various sections of our country, it should be accorded an important place in Americanization work. The vast majority of immigrants seek America because of economic motives. Why not point them to some of our potentialities and accomplishments through the avenue of Economic Geography? Other aspects of geography, i. e., social, regional, physical, mathematical, will function in classifying the analyses stimulated by the economic theme.

It is recognized by all educators that the learning process is largely a matter of sensing experiences. Units of study in modern pedagogy are units of experience. The best teaching demands the active participation of the child in the solving of real or vicarious problems and projects.

In progressive schools today the better type of teaching problems, problem solving, dramatization, socialized discussion-are to be found in geography classes in both the elementary and secondary schools. Geography, because it simulates real life, lends itself to all modern methods of instruction. It is an excellent medium for the establishment of correct habits of thinking and the development of intellectual honesty, more desirable by far than the acquiring of facts of any sort. Geography expands the mental horizon, deepens the sympathies by revealing the relation of one's work to the remainder of the social process, develops intellectual hunger, stimulates the imagination, broadens the general understanding, creates many-sided interests in direct and vicarious experiences, and encourages cooperation with the whole.

\section{Geography as a "Core" Subject}

Geography has long been recognized as a synthetic subject because of its intimate relation to the social, biological, and physical sciences. It is rooted in so wide a variety of interests that its facts and prin- 
ciples may be used as the "core" in the solution of many of the vicarious problems and in the organization of studies that deal with industries, trade and transportation, and international affairs. It offers a logical, usable, well established, easily comprehended scheme of organization of the material dealing with human activities in the fields listed above and in many others. Lack of balanced organization is one of the shortcomings of much of the teaching in the composite courses in social studies.

\section{Objectives in Junior High School Geography}

Grouping objectives under Knowledge, Habits, and Appreciation is for the convenience of adult analysis of the teachinglearning process. As the pupils experience the geography course, however, they will not attain those objectives in isolation, one from another. As they acquire knowledge, they will be receiving training in desirable habits of work and will be developing an appreciation (emotionalized insight) of life's values. "Knowledge Objectives" are listed first only because they furnish raw material out of which the habits and appreciations are built.

\section{Knowledge Objectives}

1. Knowledge of the economic activities of the pupil's own community and his country at large

2. A knowledge of the major economic activities of the various peoples of the world, stressing the relations of the work of the individual to the world's work, thus dignifying work and assisting the child in his choice of a life career by helping him to find his own personal interests

3 . Knowledge of the immense potentialities of our country and of the numerous opportunities which it offers for vigorous, thoughtful men and women

4. Knowledge of the extent and ways in which environment promotes well being

5 . Knowledge of the nations of the world, of their interdependence and of the necessity of their living together as a world family

6. Knowledge of world happenings

7. Knowledge of the specific usefulness of the various maps employed in school work, home, public libraries and the business world

8. Knowledge of the sources of first hand geographic data, with specific usefulness of each type, and of the important centers conducting geographic investigation, exploration, and publication

\section{Habits}

1. The habit of "sizing up" situations with an interest in discovering their geographic aspect

2. The habit of using geographic tools, such as book of reference, pictures, graphs, verbal material, specimens, in seeking information on the topic at hand, and to develop the ability to assemble data, weigh facts, draw conclusions, and express opinions

3 . The habit of applying geographic principles whenever practicable, in the interpretation of problems and events of current interest

4. The habit of suspended judgment

5. The habit of reading geographic literature in leisure time

\section{Appreciations}

1. An appreciation of the fact that we are living in an age characterized by rapid changes in man's relation to his physical environment, to society, to the state, and to the world

2. Sympathetic appreciation of the elements of the physical environment which help to explain the work and play activities of man in specific environments

3. An appreciation of the fact that in a country as large as ours with problems peculiar to sections playing a large part in national politics a spirit of tolerance is essential to state and national stability

4. An appreciation of how the physical environment necessitates the interdepend- 
ence of people and nations as man's wants become more numerous

5. An appreciation of the way in which the physical environment may handicap or significantly encourage a country to take its place in world affairs

6. An appreciation of the interest geography gives to one's reading

7. An appreciation of our resources and potentialities in comparison with those of other nations, of our accomplishments with theirs, of our economic and social conditions with theirs

8. An appreciation of the great need of the conservation of our natural resources, and our co-operation with other nations in establishing a world conservation policy

9. An appreciation of the value of good government as a factor in the utilization of the resources of an environment

10. An appreciation of the obligations the United States as a world power and a member of the great family of nations has to all peoples

11: An appreciation of the great value of geography in making travel interesting and profitable

IV. The Junior High School Curriculum

The committee recommends two years of geography in the junior high school as the minimum to carry out the objective listed above. We suggest two major fields of study for these two years of work as here listed under $\mathrm{A}$ and $\mathrm{B}$.

\section{A. Resources and Industries of the United States and Their World Relations}

This group of topics is intended to give an understanding of the varied natural environments of the United States, the human adjustments to each, and need of adjustment as the population increases. The beginning of an understanding of geographic laws and principles should come about as a natural result of the study and interests and activities of man in these environments. This unit should also develop an appreciation of the interdependence of peoples with- in a national group, and an appreciation of the interdependence of nations through a knowledge of the social and trade relations of the United States and the rest of the world.

\section{B. The Interdependence of Nations and Regions}

The purpose of the geography work in the second year is to assist the junior high school child to investigate the relation between life and the natural environment in the various regions and countries of the earth in order that he may come to see that man's economic activities are largely adjusted to the physical conditions and that nature affects the interdependence of nations and regions.

This two year curriculum may be simplified to fit into the second cycle of the "Eight-four Plan."

Some Suggestions to the Curriculum Maker as to the Content and Method of Junior

\section{High School Geography}

In working over the various units of study listed below, one should include only such material as is concrete and definite and of such nature that the pupils can recognize its worth. The material must be genuine and up-to-date: It should possess strong child interest.

One should endeavor to select such material and organize and teach it in such a way as to give the pupils the conscious thought that they are meeting with real and generally new experiences. The emphasis on junior high school geography should be rightly on the exploratory, vocational, cultural, and citizenship training values. One should make no attempt at an exhaustive study of one topic, but should treat each topic with sufficient fullness so that there will be left in the child's mind lasting impressions.

One should provide for the free use of all known "supplementary" and "dynamic activities," such as field excursions, indi- 
vidual investigations, group reports, interviews with authorities, laboratory studies, and current events.

The boundaries imposed by "subjects" should not be permitted to hamper unnecessarily the teacher and pupils in following out a lead and developing associations and natural relationships.

\section{A Suggested List of Topics}

The committee believes it advisable to present a tentative list of topics that school administrators can better understand the value of the curriculum suggested. It is not the idea of the committee to recommend a nationally approved list of topics, merely to present samples of the types of units of study that may be used to realize the objectives listed.

A. Resources and Industries of the United States and Their World Relations

In so far as possible each unit should be based on local industries as offering concrete, accessible types.

1. The Wide Variety and Wealth of our

Resources

Rank among nations in a few products as types

Per capita wealth of nations

Importance of resources

The inventive genius and working efficiency of Americans

Our rank among nations

2. The Physical Basis of our Wealth and

Power

Large area-its effects

Wide extent of usable land

Favorable and stimulating climate

Fuels and other minerals

Natural transportation facilities

Location for foreign commerce

3. The Distribution of Population in the

United States

Part played by geography in the movement of frontiers

4. Transportation in the United States A century of improvements in transportation
From trail to railroad and auto track

Canoe to ocean liner and tramp steamer

The conquest of the air.

5. Our Ability to Produce and Distribute Foods

Geographic factors in the production of foods

The movement of foods to markets

6. United States as a Manufacturing $\mathrm{Na}$ tion

From handwork to machine

Use of tools, implements, and machines

7. Sources and Uses of Power Man, animal, fuels, wind and water

8. The Iron and Steel Industry Mining

Metal manufactures

9. Our Ability to Clothe Ourselves

10. Our Forest Resources

The lumber, woodworking and paper industries

Conservation of forests

11. Building Materials and their Production

12. Commerce of the United States

The chief railway systems

Our use of the waterways

Coastwise traffic

Some of the more important ports of our country

13. Our Independence of and Dependence upon other Nations, largely a review

Suggestions for Interpreting Above Topics

1. The topics in this section are not to be considered in detail; they are to serve rather as an introduction to the course. They are intended to motivate the pupils in their choice of problems. Graphs which portray relative rank among nations are to be preferred to the study of exact figures.

2. These topics also are to be considered in a broad and general sense: they must serve to give the pupils a background of the 
country as a whole, upon which further topics may be elaborated.

3 . Study of population maps will introduce the problem "Why do many people live so close together here and so far apart in other places?" The solution of this problem will involve the consideration of living conditions in mountains, deserts, etc. Causes of fluctuation in population are involved.

The study of population maps of 1790 , 1850 , etc., will show the spread of population westward. The influence of passes and natural waterways will explain the movement of the frontier and the directions of the movements. The influence of discoveries, inventions, in opening up new territories, must be considered.

4. Transportation of commodities across the United States is not to be considered here, because centers of production and markets have not yet been definitely located. The emphasis is to be placed rather upon modern means of transportation by land, water and air. Brief historical sketches of the growth of these means should be introduced. A more detailed study of specific centers and routes of trade is deferred until section 12 of this course.

5. This topic calls for a study of the production of certain important food crops, as fruits, wheat, etc., as well as fish and cattle, the choice of which is left to the discretion of the individual teacher. The influences of such geographic features as surface, soil, climate, etc., upon the production of the product is to be considered, as well as man's adaptation to the environmental factors such as irrigation, drainage, etc., which make possible increased production, and production under unfavorable conditions. Specific routes of trade between the producer and consumer in dense population centers are to be studied.

6. Graphs and charts will show the present importance of the United States as a manufacturing nation, centers of dense population being also manufacturing centers. Present day machinery, such as looms, the cotton gin, farm implements, the work of necessity and genius should be studied. Pupils should be led to appreciate the comforts over older hard methods, which have been brought about through these inventions. Since the teacher is at liberty to choose his topics according to individual need, or child interest, it is suggested that perhaps this topic might be more profitably deferred until later, when all the elements necessary to a manufacturing community have been studied, these elements being: presence or accessibility of raw materials, ready market, power, labor, means of communication with market and with fertile hinterland.

7. Topic 7 involves a study of the means by which work can be done in the United States. Foremost is man power, and without delving too deeply into the realms of sociology and economics, pupils should realize and appreciate the initiative, energy and creative genius of Americans, and the influence of climate upon these characteristics, encouraging or discouraging as it does, certain types of 1mmigrants. Animal power in certain agricultural and forest regions should be noted as a natural adjustment to geographic conditions. Wind mills of the prairies, the recently invented rotorship, the importance of wood as a fuel in certain sections, then the great stores of water power among our mountains, our gas, coal and oil resources should also be studied.

8. The centers of iron production and the comparative value of the iron mines of the United States and other countries should be studied and drilled through the use of maps and graphs. Processes of iron mining, its dependence upon coal mining, the manufacturing processes and centers of steel and machinery manufacturing, should receive only brief consideration. A study of social conditions among miners in mountain sections will lead to a sympathy with these laborers and an understanding of their problems.

9. This topic should be treated in a way 
similar to topic 5. Manufacturing and routes of trade can be more fully treated here, however, because of the accumulated background.

10. Forest areas of the United States and the principal types of trees should be located in the United States. The dependence of forest growth upon surface and climate should be stressed, as well as different ways of lumbering for different sections of our country. Hardwoods, naval stores, paper pulp, nursery plants, dye woods should all be stressed as forest products. The belief in the necessity of farming tree crops rather than in mining forests should be inculcated. The necessity of forest conservation as a means of influencing our climate and preserving our soils should be indelibly impressed. Pupils should feel it their patriotic duty to transmit their forest "not only not less, but greater, better and more beautiful than they were transmitted to them." Foreign markets for United States lumber and large lumber ports should be included.

11. Areas of building stone production should be studied, using maps. Methods of quarrying, use of various stones in building should also be used. This topic includes also such manufactured materials as brick, concrete, pottery and glass.

12. Having studied the resources and industries of the United States, this consideration of the means of transporting raw and manufactured material comes more as a summary and application of what has been previously studied. Note that topic 4 deals with general means of transportation and with historical changes in method, whereas topic 12 deals with actual commerical facilities as they exist today in our country.

13. At the conclusion of the course, the teacher should be able to judge of the child's appreciation of our great and necessary dependence upon other nations for a market for our goods, and for a source of raw materials as well as their dependence upon us. A knowledge of facts alone will not suffice; understanding and appreciation of world interdependence must have been inculcated. Specific cases should be stressed and cited. The child should feel the same appreciation toward different sections of our country and toward all people engaged in different industries.

\section{B. The Interdependence of Nations and Regions}

1. Many Lands Supply Our Needs (Products used in our community)

Why there is commerce Magnitude of present day commerce Major products of commerce

2. Studies of a Few Typical Products of Commerce

Production (primary and secondary) and movement of rubber, sugar, leather, vegetables, oil and railroad equipment

3. World Commerce

Products of modern commerce

Commodities and traffic routes of the past

Traffic routes of today

4. The Machinery of Commerce-Transportation and Communication

Human portage and pack animals

Evolution of ships

Railroads, distribution as to continents and countries, their efficiency

Work of consular service

Postal, cable and wireless service

Coaling stations

Government aids to navigation

New York as a modern port and its equipment

Story of the growth of manufactures, source of raw products, capital

5. Type Regions and Countries Great Britain (and Northern Ireland) as a modern manufacturing and commercial nations

Textile industries, iron and steel, machinery, ship-building

Agricultural conditions at home

Commerce in foods and raw products 
Britain's investments in opening undeveloped regions

British Dominions and Coloniesinterrelationships

London as an entrepot port

Position of coal in foreign trade

Relation of navy to commerce

How war disturbs British industry and trade

Russia-an agricultural country of the temperate zone

The Philippines-tropical lands, how used by man

Persia-Land of little rain

Amazon Basin and Arctic Landsregions of little commerce and development

India-An old, densely populated and retarded country

6. A Study of Selected Regions and Countries

The following list of regions and countries should be considered as the maximum

Canada-Our Northern Neighbor

Mexico and the Caribbean Lands

The Andean Countries

The Temperate (intermediate) Zone Countries of South America

The Coffee Region of Brazil

France and Belgium

The Scandinavian Countries

The Western Mediterranean Lands

The Balkans

Central Europe

Undeveloped Siberia

Southwest Asia

China and Manchuria

Japan

The suggestions following part $\mathrm{A}$ are, in the main, applicable also to B. From these the teachers should have gained sufficient ideas of the purpose of these topics to enable them to work out their own problems.
COMMITTEE OF THE NATIONAL COUNCIL OF GEOGRAPHY TEACHERS

(Appointed by Board of Directors, Madison Meeting, 1925)

Angela Broening

Supervisor in Junior High School, Baltimore, Maryland

R. G. Buzzard

State Normal University, Normal, Illinois

LEONARD PACKARD

Teachers College of the City of Boston, Massachusetts

HAzel Shiet.dS

Columbia University, New York City

Zoe E. Thralls

State Normal School, Indiana, Pennsylvania

A. E. PARKins, Chairman

George Peabody College for Teachers, Nashville, Tennessee

Additional copies of this report may be obtained from the Treasurer of the National Council of Geography Teachers-Dr. D. C. Ridgley, Clark University, Worcester, Massachusetts. Price is ten cents.

\section{WHAT ART MEANS TO ME}

I feel within an impulse, perhaps that divine impulse which has moved all races, in all ages and in all climes, to record in enduring form the emotions that stir within. I may model these emotions in clay, carve them in wood, hew them in stone, or forge them in steel; I may weave them in textiles, paint them on canvas or voice them in song; but whichever I do I must harken always to the song of the lark and the melody of the forest and stream and respond to the color of the rose and the structure of the lily, so that my creation may be in accord with God's laws and the universal laws of order, perfect fitness and harmony. Moreover, I must make my creation good and honest and true, so that it may be a credit to me and live after I am dead, revealing to others something of the pleasure which I found in its making. Then will my creation be art whether I be poet or painter, blacksmith or cobbler, for I shall have labored honestly and lovingly in the realization of an ideal.

\section{Valentine Kirby}

